\title{
Ankylosis of Permanent First Molar: Diagnosis by Cone Beam Computed Tomography
}

\author{
Anquilosis del Primer Molar Permanente: Diagnóstico por \\ Tomografía Computarizada con Haz Cónico
}

\author{
Eliana Dantas da Costa'; Priscila Dias Peyneau'; Francielle Silvestre Verner2; \\ Rafael Binato Junqueira3; Solange Maria de Almeida' ${ }^{3}$ \& Glaucia Maria Bovi Ambrosano ${ }^{4}$
}

DA COSTA, E. D.; PEYNEAU, P. D.; VERNER, F. S.; JUNQUEIRA, R. B.; DE ALMEIDA, S. M. \& AMBROSANO, G. M. B. Ankylosis of permanent first molar: Diagnosis by cone beam computed tomography. Int. J. Odontostomat., 11(3):319-325, 2017.

ABSTRACT: Ankylosis is an anomaly of tooth eruption characterized by the fusion of cementum and alveolar bone, and may affect from small regions to the entire root surface. Clinical assessment combined with imaging exams can aid diagnosis. Radiographic testing enables assessing only proximal regions of possibly affected roots. Whereas cone beam computed tomography (CBCT) allows a three-dimensional assessment of axial, coronal, and sagittal planes of all dental extension, eliminating thus overlapping images and helping to confirm the correct diagnosis. The present study contains a case report of a male patient with ankylosis in tooth 16 diagnosed by CBCT, aiming at providing information for dentists about this anomaly, its characteristics and situations in which CBCT should be indicated.

KEY WORDS: dental ankylosis, diagnosis, cone beam computed tomography.

\section{INTRODUCTION}

Dentoalveolar ankylosis is an anomaly of dental eruption, caused by mechanical failure of eruption (Frazier-Bowers et al., 2007), characterized by the fusion of cementum and alveolar bone (Loriato et al., 2009; Pithon \& Bernardes, 2011; Chae \& Paeng, 2012; Guimarães et al., 2015; Mohadeb et al., 2016), with destruction of the periodontal ligament (Pithon \& Bernardes; Lin et al., 2014) and gradual replacement by bone tissue (Alves et al., 2011; Bertl et al., 2012; Silva, 2015).

Ankylosis can affect both sexes (Silva) and it is more frequent in deciduous teeth (10:1) (Loriato et al.; Cohen-Levy et al., 2011; Bertl et al.; Silva), with frequency between $1.5 \%$ and $9.9 \%$ (Atobi et al., 2009; Loriato et al.), especially when the permanent successor is missing (Bertl et al.), affecting mainly mandibular deciduous first molars (Loriato et al.; Alves et al.; Bertl et al.; Parisay et al., 2013), followed by second mandibular and maxillary deciduous molars (Parisay et al.).

Traumatic lesions are considered the main factor for development of ankylosis (Atobe et al., 2009; Cohen-Levy et al.; Chae \& Paeng; Gault et al., 2013; Lin et al.; Mohadeb et al.; Silva). Moreover, these are also considered causal factors: metabolic disorders, local deficiency in vertical alveolar bone growth (Atobe et al.; Loriato et al.; Cohen-Levy et al.; Alves et al.; Parisay et al.; Lin et al.; Guimarães et al.), failure of eruption force (Alves et al.), genetic factors (Atobe et al.; Cohen-Levy et al.; Chae \& Paeng; Lin et al.; Guimarães et al.; Silva), focal inflammation/infection, chemical/thermal irritants (Cohen-Levy et al.; Gault et

\footnotetext{
${ }^{1}$ Division of Oral Radiology, Department of Oral Diagnosis, Piracicaba Dental School, State University of Campinas, Piracicaba, São Paulo, Brazil. ${ }^{2}$ Division of Oral Radiology, Department of Dentistry, Federal University of Juiz de Fora, Advanced campus Governador Valadares, Juiz de Fora, Minas Gerais, Brazil.

${ }^{3}$ Division of Endodontic, Department of Dentistry, Federal University of Juiz de Fora, Advanced campus Governador Valadares, Juiz de Fora, Minas Gerais, Brazil.

${ }^{4}$ Department of Social Dentistry, Piracicaba Dental School, State University of Campinas, Piracicaba, São Paulo, Brazil.
} 
al.; Parisay et al.; Silva), and soft tissue pressure (Atobe et al.; Cohen-Levy et al.). It should also be noted that ankylosis may affect teeth that have been extracted and subsequently reimplanted (Takahashi et al., 2005; Chae \& Paeng; Silva), but in these cases ankylosis is not considered an anomaly of dental eruption.

The differential diagnosis of ankylosis includes other types of eruption disorders, such as: impaction, primary retention, secondary retention and primary eruption failure (Janssen et al., 2014). In the impaction, the eruption is impaired due to the presence of a physical barrier or due to the ectopic position of the tooth. Primary and secondary retentions are caused by failures in the eruption mechanisms, and in the primary type, the interruption of the eruption occurs before the tooth reaches the gingival level. In the secondary, the tooth ceases the eruption when reaching the gingival level (Magnusson \& Kjellberg, 2009). The primary failure of the eruption mainly affects the posterior teeth (Rhoads et al., 2013). In such cases, the tooth may erupt partially, becoming relatively submerged or may not erupt (Frazier-Bowers et al.; Smith et al., 2012). Although there is no cement union to the alveolar bone in these cases, they present clinical features very similar to ankylosis.

However, in the primary failure, the treatment is more complex, frequently involving all the teeth adjacent to the affected tooth, resulting in lateral opened bite (Frazier-Bowers et al.; Rhoads et al.; Smith et al.). This disorder is caused by genetic changes associated with the parathyroid hormone (PTHPR1) (Rhoads et al.; Smith et al.).

Primary diagnosis of ankylosed teeth is made by clinical assessment through mobility and percussion tests, in these cases the tooth makes a metallic sound (Campbell et al., 2005; Lim et al., 2008; Berl et al., 2012; Gault et al.; Lin et al.; Mohadeb et al.; Silva), unlike healthy teeth, in which the sound is neutralized by periodontal ligament (Berl et al., 2012; Parisay et al.; Silva).

However, since only one third of the patients present these clinical signs (Cohen-Levy et al.; Lin et al.), it is necessary to carry out imaging tests to confirm clinical signs of ankylosis. Although periapical x-rays are daily used in dental clinics, their value is limited for diagnosisof ankylosed teeth (Paris et al., 2010; CohenLevy et al.; Berl et al., 2012; Cha et al., 2012; Gault et al.; Lin et al.; Mohadeb et al.), because ankylotic areas only visible when it is present in proximal surfaces of the root, not being possible to identify lingual/palatal and buccal surfaces (Takahashi et al.; Cohen-Levy et al.; Berl et al. 2012; Silva et al.). Besides, in this examination the presence of ankylosis becomes evident only when at least $20 \%$ of the root surface is affected (Campbell et al.; Cohen-Levy et al.; Mohadeb et al.).

Whereas computed tomography (CT) is considered superior to radiography (Kirziolu et al., 2007) because of the possibility of a three-dimensional evaluation of the structures, allowing precise observation of the whole extent of the root surface (Paris et al.; Chae \& Paeng; Silva), the degree of irregularity of the root, and the relationship between the root and the adjacent teeth (Gault et al.), helping in early diagnosis of ankylosed teeth. With equal accuracy, cone beam computed tomography (CBCT) can also be used for the diagnosis of ankylosed teeth (Balaji, 2013; Hashim et al., 2013; Silva), having as advantage the lower dose of radiation (Holberg et al., 2005; Balaji; Kamburoglu, 2015; Silva) and lower cost compared with CT (Holberg et al.; Balaji; Kamburoglu).

In the initial stages, the primary failure of eruption and ankylosis may have similar clinical presentations (Frazier-Bowers et al.). With the lack of accessibility of genetic tests in dental offices to confirm the occurrence of primary failure (Rhoads et al.), it is important resorting to accurate imaging methods, such as CBCT, to distinguish these two eruption disorders, providing the correct diagnosis and the best treatment options for patients.

Considering the limitation in the literature concerning the diagnosis of ankylosis using CBCT (Silva), the aim of this study was to provide information to dentists on the importance and the situations when to use CBCT in diagnosis of ankylosed teeth.

\section{CASE REPORT}

Male patient, 16 years old was referred for clinic of the Oral Radiology to perform CBCT, in order to plan the next steps of the orthodontic treatment. When he was referred, infraocclusion of the maxillary right first molar was reported and it did not respond to orthodontic forced eruption. The patient did not report pain and remembered the trauma that occurred in the region, when he was a child during a football game. The patient did not present relevant data regarding systemic 
DA costA, E. D. ; PEYNEAU, P. D.; VERnER, F. S.; JUNQUEIRA, R. B.; DE ALMEIDA, S. M. \& AMBRosANO, G. M. B. Ankylosis of permanent first molar: Diagnosis by cone beam computed tomography. Int. J. Odontostomat., 11(3):319-325, 2017.

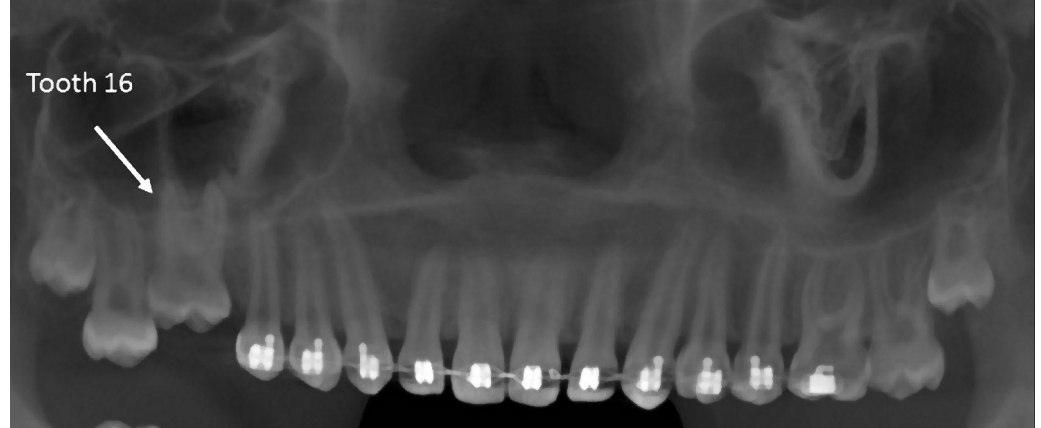

Fig. 1. CBCT panoramic reconstruction. Infraocclusion of tooth 16 in contact with the maxillary sinus (white arrow).

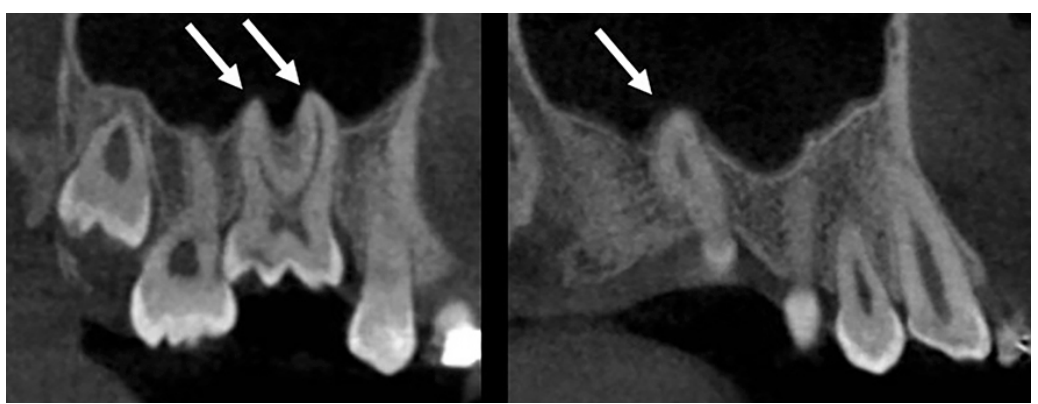

Fig. 2. CBCT sagittal planes showing absence of periodontal ligament space on tooth 16 buccal root $(A)$ and palatal root $(B)$.

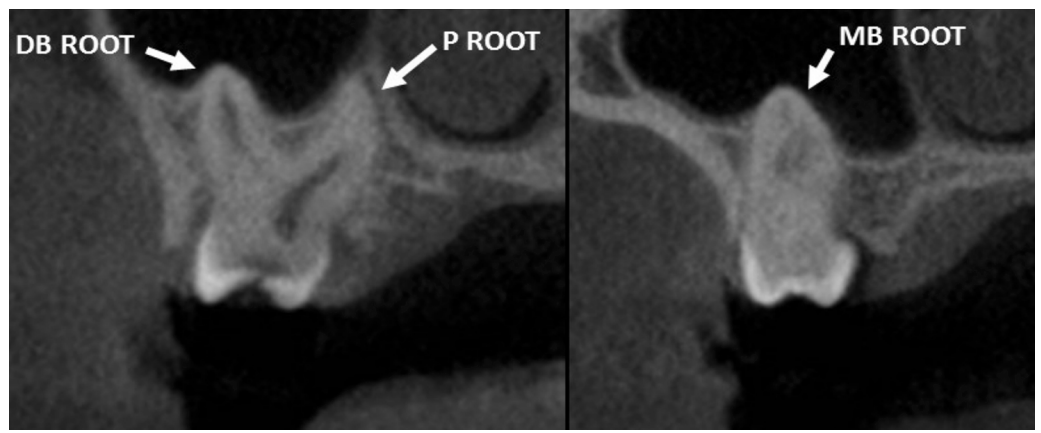

Fig. 3. CBCT coronal plane showing absence of periodontal ligament space in the roots. (A) Distobuccal and palatal root and (B) Mesiobuccal root. situation and there were no cases in the family of infraocclusion of teeth.

The CBCT was conducted on ICAT ${ }^{\circledR}$ CB500 (Imaging Sciences, Hatfield, PA) under the acquisition protocol: $120 \mathrm{kVp}, 5 \mathrm{~mA}, 0.25 \mathrm{~mm}$ voxel, and Field of View (FOV) of $13 \times 8$. Multiplanar reconstructions (MPR) were obtained and in the panoramic reconstruction, in sagittal and coronal planes, it was observed that in addition to unerupted teeth 18 and 28, the patient had tooth 16 partially erupted, with its roots in contact with the maxillary sinus and absence periodontal ligament space along the roots (Figs. 1, 2, and 3 ). It is possible to verify still that the distal surface of the crown of tooth 16 was in contact with the mesiocervical area of tooth 17, causing external resorption. The hypodense image identified in the occlusal surface is a dental cavity affecting enamel and dentine (Fig. 4). Comparing clinical signs, symptoms and CBCT image, the hypothesis of dental ankylosis was suggested, because infraocclusion of tooth 16 was below the contact area of the teeth 17 and 15 (Fig. 5).

The ethics committee on human research exempted this study approval since only СВCT images would be disclosed without the possibility of patient identification.

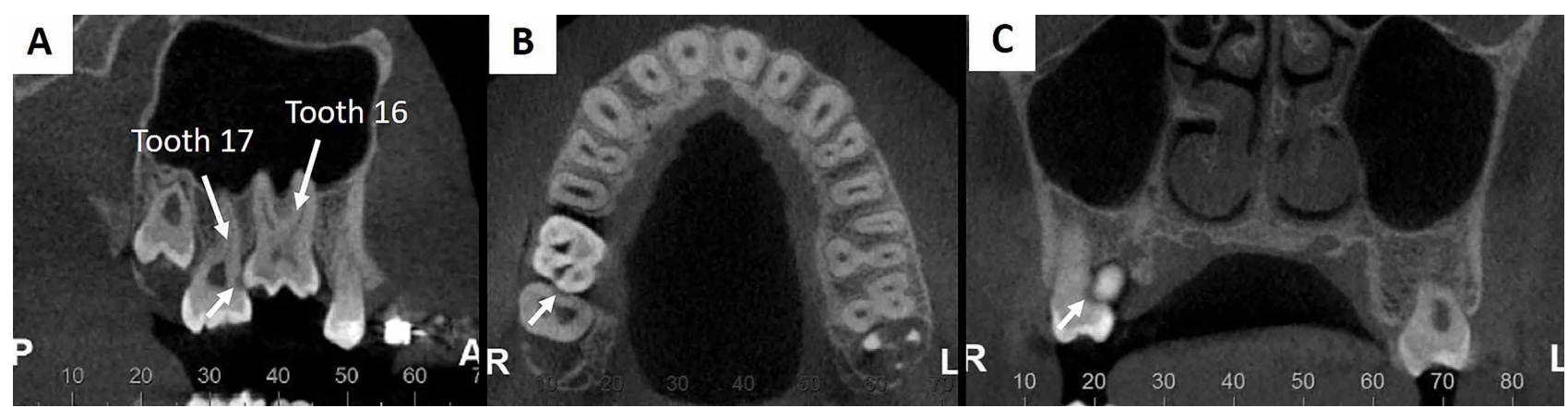

Fig. 4. CBCT sagittal (A), axial (B) and coronal (C) planes showing hypodense image on cervical region of tooth 17, compatible with external resorption (white small arrows). 


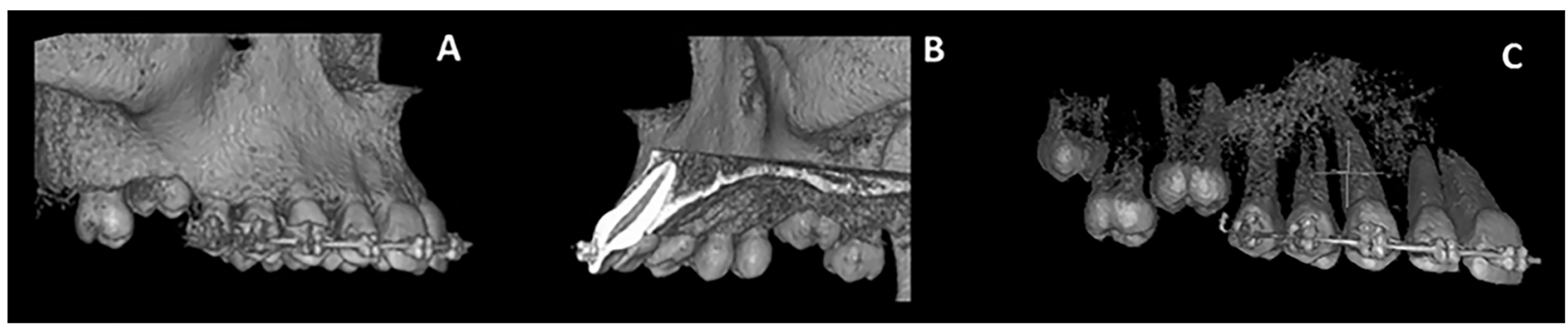

Fig. 5. Three-dimensional (3D) reconstructions of right hemi maxilla. A) Buccal view; B) Palatal view; C) Buccal view: Use of bone extraction tool.

\section{DISCUSSION}

Ankylosis is defined as the anatomical fusion of cementum with alveolar bone (Loriato et al.; Pithon \& Bernardes; Chae \& Paeng; Guimarães et al.; Mohadeb et al.), due to the destruction of the periodontal ligament (Pithon \& Bernardes; Lin et al.), occurring at any time during the course of eruption (Mohadeb et al.).

Ankylosis is a common complication after traumatic episodes (Atobe et al.; Cohen-Levy et al.; Chae \& Paeng; Gault et al.; Lin et al.; Mohadeb et al.; Silva) causing a severe injury in the periodontal ligament, which does not regenerate (Gault et al.), triggering an inflammation process (Mohadeb et al.) and a gradual replacement by alveolar bone tissue (Lin et al.). Although the incisors teeth are more susceptible to ankylosis after a trauma (Cohen-Levy et al.; Lin et al.), in the case reported the patient reported trauma in the posterior region of the face, which may have triggered ankylosis during eruption of tooth 16 . Besides, another peculiarity of the present case is that ankylosis occurred with a permanent tooth, because it rarely affects permanent dentition (Atobe et al.; Loriato et al.; Cohen-Levy et al.; Silva) and the frequency in permanent molars is $0.06 \%$ (CohenLevy et al.).

As observed in the case reported, the more evident clinical sign of ankylosis is the presence of infraocclusion (Cohen-Levy et al.; Pithon \& Bernardes; Bertl et al.; Gault et al.; Lin et al.; Guimarães et al.; Silva), as a result of the continuous vertical growth of the alveolar bone (Bertl et al.), which can be classified into slight, when the occlusal face is up to $2 \mathrm{~mm}$ from the occlusal plane; moderate, when the occlusal face of the ankylosed tooth is at the level of the contact surface of adjacent teeth; and severe, when infraocclusion is below the contact area of the adjacent teeth (Alves et al.; Parisay et al.).

In the present case, as in the primary eruption failure, a posterior tooth was affected. However, unlike the primary failure, normal eruption of adjacent teeth was observed. Besides, the CВСТ exam confirmed the presence of ankylosis in the roots of the teeth. Thus, once the crown of the tooth was below the point of contact of teeth 17 and 15, it was suggested that the ankylosis occurred early in the phase of the eruption process during the patient's childhood.

Therefore, depending on the level of infraocclusion, it may trigger several clinical implications during jaws development and growth, e.g., open bite (Atobe et al.; Loriato et al.; CohenLevy et al.; Alves et al.; Bertl et al.; Lin et al.; Guimarães et al.), inclination of the adjacent teeth, overeruption of the antagonist tooth (Kirziolu et al.; Cohen-Levy et al.; Pithon \& Bernardes; Alves et al.; Bertl et al.; Lin et al.; Guimarães et al.), vertical alveolar bone loss (Lin et al.), and a shift of the dental midline to the affected side (Loriato et al.; Cohen-Levy et al.; Pithon \& Bernardes, 2011; Lin et al.).

Regarding other complications, there is greater difficulty in cleaning due to the tooth position below the occlusal plane (Pithon \& Bernardes; Alves et al.; Bertl et al.), causing food impaction and higher caries risk, and periodontal disease affecting adjacent teeth (Takahashi et al.; Loriato et al.; Silva). Moreover, because the cementum of the ankylosed tooth is in direct contact with the alveolar bone, its root is more susceptible to suffer bone resorption by replacement (Takahashi et al.; Loriato et al.; Silva). Another problem identified in our case report was the presence of resorption of the crown of tooth 17 , probably caused by pressure exerted by tooth 16 . 
Ankylosis treatment depends on infraocclusion degree. In slight cases, follow up is recommended (Lim et al.; Cohen-Levy et al.; Pithon \& Bernardes; Alves et al.; Parisay et al.). When infraocclusion is less than 5 $\mathrm{mm}$, it is possible to carry out restorative treatment with the use of restorative materials or prosthetic crowns for reestablishing dental occlusion (Lim et al.; CohenLevy et al.; Pithon \& Bernardes; Parisay et al.; Mohadeb et al.). On the other hand, if the infraocclusion is severe, the treatment is more complex and has the following options: orthodontics associated with luxation although there are risks of fracture, recurrence of ankylosis and endodontic problems (Lim et al.; CohenLevy et al.; Pithon \& Bernardes; Parisay et al.; Mohadeb et al.); segmental osteotomy; ankylosed tooth transplantation (Cohen-Levy et al.; Gault et al.; Mohadeb et al.); and extraction followed by implant (Lim et al.; Cohen-Levy et al.; Pithon \& Bernardes; Parisay et al.; Mohadeb et al.). Although in adults ankylosis treatment is less challenging due to the possibility of rehabilitation with prosthesis or implants (Mohadeb et al.), the patient has not yet reached skeletal maturity, making this kind of intervention impossible.

It is worth mentioning that surgical extraction often causes bone defects in the alveolar area affected by ankylosis (Lim et al.; Pithon \& Bernardes). In the present case report, the close relationship of tooth 16 roots with the floor of the maxillary sinus may also hinder their surgical extraction and lead to complications such as oroantral communication.

According to Lin et al. it is difficult to predict if a tooth that suffered trauma will have ankylosis in the future, and as in the present case, it can be noticed only after many years when functional and aesthetic complications become evident. However, ankylosis early diagnosis is difficult, for in the beginning areas absence periodontal ligament are small and the tooth still presents mobility (Cohen-Levy et al.).

Besides, percussion clinical tests and metallic sound produced are only reliable in about one-third of the cases (Cohen-Levy et al.; Lin et al.) and are strictly dependent on the professional's judgment and experience (Campbell et al.; Cohen-Levy et al.). Moreover, radiographic examination is also inaccurate (Kirziolu et al.; Cohen-Levy et al.; Bertl et al.; Chae \& Paeng; Mohadeb et al.), because absence of the periodontal ligament is identified only when $20 \%$ of the root surface is ankylosed (Campbell et al.; CohenLevy et al.; Mohadeb et al.), even when present only in proximal surfaces (Takahashi et al.; Cohen-Levy et al.; Bertl et al.; Silva et al.). Also, it is not possible to visualize the root bifurcation area (Silva). In the present case, because the tooth was a molar tooth, radiographic diagnosis is even more challenging, for it is a multiradicular tooth due to overlapping structures.

Hence, ankylosis diagnosis may occur incidentally, when the patient undergoes an orthodontic treatment and the tooth does not respond to orthodontic movement (Takahashi et al.; Lim et al.; Loriato et al.; Alves et al.; Chae \& Paeng; Gault et al.). Nevertheless, CT examination is essential for diagnosis confirmation and for exact identification of the root region affected by ankyloses (Chae \& Paeng). In this sense, as CBCT has accuracy similar to CT for bony structures (Stutzki et al., 2015), and for being a three-dimensional imaging examination widely used in Dentistry (Balaji; Kamburoglu; Silva), for precisely assessing dental anatomy and bone structures affected by ankylosis, it can also be used in the diagnosis of dental ankylosis (Holberg et al.; Balaji; Silva), as observed in the present case.

In order to be acknowledged with the subject, we made a research in the PubMed database, using the following key words: "dental ankylosis", "diagnosis", "dental trauma", "computed tomography", and "cone beam computed tomography". Studies on diagnosis of ankylosis using CT are limited (Kitai et al., 2003; Kirziolu et al.; Paris et al.; Chae \& Paeng; Gault et al.) and even more using CBCT (Balaji; Tsukiboshi \& Tsukiboshi, 2014). However, for identifying the root region extent and exact location where ankylosis is present, the examination by three-dimensional imaging is essential (Paris et al.; Gault et al.; Silva), especially in severe cases of ankylosed molar teeth (Berl et al., 2012).

Thus, CBCT provides this diagnosis with lower radiation doses (Balaji; De Cock et al., 2015; Kamburoglu) and lower costs than CT (Balaji; De Cock et al.; Kamburoglu; Stutzki et al.), besides being frequently requested in orthodontics (Kamburoglu), specialists who are often involved in the treatment of dental, occlusal, and aesthetic complications caused by ankylosis (Chae \& Paeng). In complex cases, CBCT may also be required for surgical treatment of ankylosed teeth (Balaji), when the tooth is near noble structures, e.g., the mandibular canal (Kirziolu et al.) or the maxillary sinus, as in the present case. CBCT is therefore an important diagnostic tool for examination and treatment planning (Balaji), safe for professionals and patients as well. 


\section{CONCLUSION}

The importance of the early diagnosis of ankylosis should be highlighted, because the maxillomandibular growth turns the orthodontic and surgical treatments more complex, due to the worsening of occlusal problems and deficiencies of the alveolar bone. In this context, the CBCT imaging allows identified with high accuracy all root surfaces affected by ankylosis and it may be requested for accurate diagnosis of the presence and location of ankylosis in molar teeth, showing anatomical details that could not be visualized in conventional radiographic techniques because of their two-dimensional nature and overlapping structures.

\section{ACKNOWLEDGEMENTS}

The authors thank the CAPES (Coordenação de Aperfeiçoamento de Pessoal de Nível Superior) for the PhD scholarship, and Espaço da Escrita (Coordenadoria Geral - UNICAMP) for the language services provided.

DA COSTA, E. D.; PEYNEAU, P. D.; VERNER, F. S.; JUNQUEIRA, R. B.; DE ALMEIDA, S. M. \& AMBROSANO, G. M. B. Anquilosis del primer molar permanente: diagnóstico por tomografía computarizada con haz cónico. Int. J. Odontostomat., 11(3):319-325, 2017.

RESUMEN: La anquilosis es una anomalía de la erupción del diente caracterizada por la fusión de cemento y hueso alveolar, y puede afectar desde pequeñas regiones hasta toda la superficie de la raíz. La evaluación clínica combinada con los exámenes de imagen puede ayudar a diagnosticar esta anomalía. Las pruebas radiográficas permiten evaluar sólo las regiones proximales de las raíces posiblemente afectadas. La tomografía computarizada de haz de cono (CBCT) permite una evaluación tridimensional de los planos axial, coronal y sagital de toda la extensión dental, eliminando así las imágenes superpuestas y ayudando a confirmar el diagnóstico correcto. En el presente estudio se presenta un reporte de caso de un paciente con anquilosis en el diente 16 diagnosticado por CBCT, con el objetivo de proporcionar información para los dentistas sobre esta anomalía, sus características y situaciones en las que debe indicarse la CBCT.

PALABRAS CLAVE: anquilosis dental, diagnóstico, tomografía computarizada de haz cónico.

\section{REFERENCES}

Alves, M. S. C.; Leite, T. H. M.; Vieira, D. R. P.; Cruz, M. C. F. N. \& Alves, C. M. C. Diagnosis and treatment of severe dentoalveolar ankylosisin primary molars: case report. Rev. Odontol. U. N. E. S. P., 40(3):154-9, 2011.

Atobe, M.; Sekiya, T.; Tamura, K.; Hamada, Y. \& Nakamura, Y. Severe lateral open bite caused by multiple ankylosed teeth: a case report. Oral Surg. Oral Med. Oral Pathol. Oral Radiol. Endod., 107(4):e14-20, 2009.

Balaji, S. M. Submerged mandibular carious deciduous second molar along with an impacted second premolar associated with an atypical inflammatory follicular cyst: a rare case report. Indian J. Dent. Res., 24(6):775-9, 2013.

Bertl, M. H.; Weinberger, T.; Schwarz, K.; Gruber, R. \& Crismani, A. $\mathrm{G}$. Resonance frequency analysis: a new diagnostic tool for dental ankylosis. Eur. J. Oral Sci., 120(3):255-8, 2012.

Campbell, K. M.; Casas, M. J.; Kenny, D. J. \& Chau, T. Diagnosis of ankylosis in permanent incisors by expert ratings, Periotest and digital sound wave analysis. Dent. Traumatol., 21(4):206-12, 2005.

Chae, J. M. \& Paeng, J. Y. Orthodontic treatment of an ankylosed maxillary central incisor through single-tooth osteotomy by using interdental space regained from microimplant anchorage. Am. J. Orthod. Dentofacial Orthop., 141(2):e39-51, 2012.

Cohen-Levy, J. Ankylosis of permanent first molars: genetics or environment? A case report of a discordant twin pair. Int. Orthod., 9(1):76-91, 2011.

De Cock, J.; Zanca, F.; Canning, J.; Pauwels, R. \& Hermans, R. A comparative study for image quality and radiation dose of a cone beam computed tomography scanner and a multislice computed tomography scanner for paranasal sinus imaging. Eur. Radiol., 25(7):1891-900, 2015.

Frazier-Bowers, S. A.; Koehler, K. E.; Ackerman, J. L. \& Proffit, W. R. Primary failure of eruption: further characterization of a rare eruption disorder. Am. J. Orthod. Dentofacial Orthop., 131(5):578.e1-11, 2007.

Gault, P. Idiopathic ankylosis-resorption: diagnosis and treatment. Int. Orthod., 11(3):262-77, 2013.

Guimarães, C. H.; Henriques, J.; Janson, G. \& Moura, W. S. Stability of interceptive/corrective orthodontic treatment for tooth ankylosis and Class II mandibular deficiency: A case report with 10 years follow-up. Indian J. Dent. Res., 26(3):315-9, 2015.

Holberg, C.; Steinhäuser, S.; Geis, P. \& Rudzki-Janson, I. Conebeam computed tomography in orthodontics: benefits and limitations. J. Orofac. Orthop., 66(6):434-44, 2005.

Janssen, K. I.; Raghoebar, G. M.; Visser, A. \& Vissink, A. Terminology and manifestations of eruption disturbances. Ned. Tijdschr. Tandheelkd., 121(4):218-26, 2014.

Kamburoglu, K. Use of dentomaxillofacial cone beam computed tomography in dentistry. World J. Radiol., 7(6):128-30, 2015.

Kitai, N.; Fujii, Y.; Murakami, S. \& Takada, K. Three-dimensional evaluation of a rare case with multiple impacted teeth using CT. J. Clin. Pediatr. Dent., 27(2):117-21, 2003.

Kırzıolu, Z.; Karayılmaz, H. \& Baykal, B. Value of computed tomography (CT) in imaging the morbidity of submerged molars: A case report. Eur. J. Dent., 1(4):246-50, 2007.

Lim, W. H.; Kim, H. J. \& Chun, Y. S. Treatment of ankylosed mandibular first permanent molar. Am. J. Orthod. Dentofacial Orthop., 133(1):95-101, 2008.

Lin, F.; Sun, H.; Yao, L.; Chen, Q. \& Ni, Z. Orthodontic treatment of severe anterior open bite and alveolar bone defect complicated by an ankylosed maxillary central incisor: a case report. Head Face Med., 10:47, 2014. 
DA COSTA, E. D. ; PEYNEAU, P. D.; VERNER, F. S.; JUNQUEIRA, R. B.; DE ALMEIDA, S. M. \& AMBROSANO, G. M. B. Ankylosis of permanent first molar: Diagnosis by cone beam computed tomography. Int. J. Odontostomat., 11(3):319-325, 2017.

Loriato, L. B.; Machado, A. W.; Souki, B. Q. \& Pereira, T. J. Late diagnosis of dentoalveolar ankylosis: impact on effectiveness and efficiency of orthodontic treatment. Am. J. Orthod. Dentofacial Orthop., 135(6):799-808, 2009.

Magnusson, C. \& Kjellberg, H. Impaction and retention of second molars: diagnosis, treatment and outcome. A retrospective followup study. Angle Orthod., 79(3):422-7, 2009.

Mohadeb, J. V.; Somar, M. \& He, H. Effectiveness of decoronation technique in the treatment of ankylosis: A systematic review. Dent. Traumatol., 32(4):255-63, 2016.

Paris, M.; Trunde, F.; Bossard, D.; Farges, J. C. \& Coudert, J. L. Dental ankylosis diagnosed by CT with tridimensional reconstructions. J. Radiol., 91(6):707-11, 2010.

Parisay, I.; Kebriaei, F.; Varkesh, B.; Soruri, M. \& Ghafourifard, R. Management of a severely submerged primary molar: a case report. Case Rep. Dent., 2013:796242, 2013.

Pithon, M. M. \& Bernardes, L. A. Treatment of ankylosis of the mandibular first molar with orthodontic traction immediately after surgical luxation. Am. J. Orthod. Dentofacial Orthop., 140(3):396403, 2011.

Rhoads, S. G.; Hendricks, H. M. \& Frazier-Bowers, S. A. Establishing the diagnostic criteria for eruption disorders based on genetic and clinical data. Am. J. Orthod. Dentofacial Orthop., 144(2):194202, 2013.

Silva, D. C. Exames por Imagem no Diagnóstico de Anquilose Alveolodentária: Relato de Caso Clínico. Trabalho de Conclusão (Especialização em Radiologia Odontológica e Imaginologia). Porto Alegre, Faculdade de Odontologia - Universidade Federal do Rio Grande do Sul, 2015.

Smith, C. P.; Al-Awadhi, E. A. \& Garvey, M. T. An atypical presentation of mechanical failure of eruption of a mandibular permanent molar: diagnosis and treatment case report. Eur. Arch. Paediatr. Dent., 13(3):152-6, 2012.

Stutzki, M.; Jahns, E., Mandapathil, M. M.; Diogo, I.; Werner, J. A. \& Güldner, C. Indications of cone beam CT in head and neck imaging. Acta Otolaryngol., 135(12):1337-43, 2015.

Takahashi, T.; Takagi, T. \& Moriyama, K. Orthodontic treatment of a traumatically intruded tooth with ankylosis by traction after surgical luxation. Am. J. Orthod. Dentofacial Orthop., 127(2):233-41, 2005.

Tsukiboshi, M. \& Tsukiboshi, T. Bone morphology after delayed tooth replantation - case series. Dent. Traumatol., 30(6):477-83, 2014.
Corresponding author:

Eliana Dantas da Costa

Division of Oral Radiology

Department of Oral Diagnosis

Piracicaba Dental School

State University of Campinas

Av. Limeira, 901

Areião, Piracicaba, SP

Zip Code 13414-018

BRAZIL

E-mail: edantasc@yahoo.com.br

Received: 21-04-2017

Accepted: 19-06-2017 